\title{
O PROGRAMA NACIONAL DE TECNOLOGIA EDUCACIONAL (PROINFO) NO CONTEXTO DA DESCENTRALIZAÇÃO DA POLÍTICA EDUCACIONAL BRASILEIRA
}

\author{
R. B. ESTEVÃO ${ }^{1^{*}}$ e G. O. PASSOS ${ }^{2}$ \\ ${ }^{1}$ Universidade Federal do Piauí \\ ${ }^{2}$ Universidade de Brasília \\ renildoe@yahoo.com.br
}

Artigo submetido em dezembro/2014 e aceito em fevereiro/2015

DOI: $10.15628 /$ holos.2015.2645

\section{RESUMO}

Este texto analisa o Programa Nacional de Tecnologia Educacional (Prolnfo), caracterizando sua engenharia institucional, em particular o modo como estabelece parceria entre a União e os entes federados. O objetivo é examinar os traços constitutivos do Prolnfo, identificando, nessa engenharia institucional, a estratégia de indução do governo federal para atrair a adesão de estados e municípios. Para tanto, recorre-se à legislação que o instituiu, além da literatura relativa à descentralização das políticas sociais num Estado federativo. Constatou-se que o modelo do Prolnfo assenta-se numa divisão do trabalho em que a União financia, coordena, acompanha e avalia, enquanto os demais entes federativos administram, executam e mantêm as ações, responsabilizando-se pelos custos de manutenção, inclusive de pessoal e instalações. É uma estratégia desenhada que favorece a montagem da infraestrutura, oferecendo os meios, complementandoos ou incentivando-os a desenvolver a introdução das novas tecnologias na educação, mas não estabelece qualquer vínculo entre a liberação de recursos e o cumprimento das atribuições pactuadas ou mesmo destas com novos aportes de recurso. Portando, a engenharia institucional, ainda que tenha patrocinado a instalação de laboratórios, isto é, tenha disponibilizado os meios para a inclusão digital desejada, não favoreceu, como objetivava o programa, o uso pedagógico das tecnologias de informação e comunicação nas redes públicas de educação básica.

PALAVRAS-CHAVE: Prolnfo. Descentralização. Federalismo. Políticas Públicas. Estratégias indutoras.

\section{THE NATIONAL EDUCATIONAL TECHNOLOGY PROGRAM (PROINFO) IN THE CONTEXT OF BRAZILIAN EDUCATIONAL POLICY DECENTRALIZATION}

\begin{abstract}
This work analyzes the National Educational Technology Program (Prolnfo), featuring its institutional engineering, in particular the way in establishing partnership between the Union and the federated entities. The aim is to examine the constituent features of Prolnfo, identifying, that institutional engineering, the federal government induction strategy to attract the accession states and municipalities. It is based to the law establishing it, in addition to the literature on the decentralization of social policies in a federal state. It was found that the Prolnfo model is based on a division of labor in which the Union finances, coordinates monitors and evaluates while other federal entities manage, execute and maintain the actions, and being
\end{abstract}

responsible for maintenance costs, including personnel and facilities. It is a strategy designed to favor the assembly of infrastructure, providing the means, complementing them or encouraging them to develop the introduction of new technologies in education, but does not establish any relationship between the release of funds and compliance with the agreed allocations or even with these new resource contributions. Porting, institutional engineering, although it has sponsored the installation of laboratories, that is, has made available the means to the desired digital inclusion, did not favor, as aimed the program, the pedagogical use of information and communication technologies in public education networks Basic.

KEYWORDS: Prolnfo. Decentralization. Federalism. Public Policy. Inducing strategies. 


\section{INTRODUÇÃO}

A Reforma do Estado, nos anos 90, impingiu mudanças na estrutura organizacional do Estado brasileiro, em particular no que se refere à gestão e execução das políticas públicas de corte social. Até o início dessa década, a gestão das políticas públicas tinha o governo federal como principal responsável; no final do período, progressivamente, muitas das atribuições foram descentralizadas, ou seja, passaram para a gestão de estados e municípios.

Essa descentralização se configura no Programa Nacional de Tecnologia Educacional (Prolnfo), instituído pelo Decreto 6.300, de 13 de dezembro de 2007, na formação de parcerias entre a União e os estados e municípios através de as secretarias de educação. O intuito, com essa comunhão de esforços, é promover o uso pedagógico das tecnologias de informação e comunicação nas redes públicas de educação básica, tendo em vista contribuir com a inclusão digital, por meio da ampliação do acesso a computadores, da conexão à rede mundial de computadores e de outras tecnologias digitais.

Para isso, estabelece as competências de cada um dos parceiros através do Decreto instituidor. À União, através da Secretaria de Educação Básica do Ministério da Educação e do Fundo Nacional de Desenvolvimento da Educação, compete, primordialmente, implantar ambientes tecnológicos equipados com computadores e recursos digitais nas escolas beneficiadas, nos termos do Art. 3으 do Decreto. As competências dos estados, Distrito Federal e dos municípios visam, inicialmente, prover a infraestrutura necessária para o adequado funcionamento dos ambientes tecnológicos implantados pela União, conforme Art. 4ㅇ do mesmo Decreto.

O modelo de descentralização estende-se à gestão por toda a fase de execução, com a previsão de que haja, em cada unidade - estado ou município - a constituição de um núcleo especializado em tecnologias de informação e comunicação (TIC) aplicadas à educação.

Este texto analisa o Programa Nacional de Tecnologia Educacional (Prolnfo), caracterizando sua engenharia institucional, em particular o modo como estabelece a descentralização, isto é, a parceria entre a União e os entes federados. O objetivo é examinar os traços constitutivos do Prolnfo, identificando, na sua engenharia institucional, a estratégia de indução do governo federal para atrair estados e municípios.

Para isso, utilizaram-se os seguintes procedimentos metodológicos: pesquisa bibliográfica e pesquisa documental. A primeira constou de livros e artigos sobre a descentralização das políticas públicas, destacando-se as referentes à educação e ao Prolnfo. A segunda abrangeu a legislação que instituiu o Programa (Portarias e Decretos) e documentos institucionais, em particular aqueles que delinearam seu desenho institucional e seu modus operandi (manuais, relatórios e instruções).

Os resultados estão organizados em quatro partes, incluindo esta introdução que é a primeira. Na segunda, expõe-se o contexto histórico do Prolnfo e delineia-se sua engenharia institucional. Na terceira, enfoca-se a temática do federalismo e das políticas educacionais brasileiras no contexto da descentralização. Por fim, analisa-se a estratégia indutora da descentralização no Prolnfo. 


\section{O PROINFO: CONTEXTO HISTÓRICO}

Inserir tecnologias no ambiente escolar e buscar usá-las no processo de ensino e aprendizagem são aspectos que vêm sendo perseguidos desde a década de 1970, quando subsídios oferecidos por universidades, como UFRJ, UFRGS e UNICAMP, ensejaram a elaboração de programas voltados para a introdução da tecnologia no campo educacional, como EDUCOM Educação e Computador, FORMAR - Formação de Recursos Humanos e PRONINFE - Programa Nacional de Informática Educativa (ANDRADE; LIMA, 1993; VALENTE; ALMEIDA, 1997), dentre outros, que tanto desenvolveram pesquisas, quanto capacitaram professores para utilizá-las.

O projeto EDUCOM, apresentado em 1983, consubstanciou-se numa "proposta interdisciplinar voltada para implantação experimental de centros-piloto como infraestruturas relevantes para o desenvolvimento de pesquisas, objetivando a capacitação nacional e coleta de subsídios para uma futura política setorial" (MORAES, 1997, p. 7). Já o projeto FORMAR, por sua vez, foi representado pela operacionalização de dois "cursos de especialização em informática na educação, em nível de pós-graduação lato sensu, realizados na UNICAMP, em 1987 e 1989, dedicados aos professores das diversas secretarias estaduais de educação e das escolas técnicas federais" (MORAES, 1997, p. 9).

Em 1989, O Ministério da Educação, por meio da Portaria Ministerial no 549/GM, formalizou-se o Programa Nacional de Informática Educativa - PRONINFE. Este programa tinha por finalidade desenvolver a informática na educação, "através de projetos e atividades, articulados e convergentes, apoiados em fundamentação pedagógica sólida e atualizada, de modo a assegurar a unidade política, técnica e científica imprescindível ao êxito dos esforços e investimentos envolvidos" (TAVARES, 2002, p. 6).

$\mathrm{Na}$ sequência, o PRONINFE cedeu lugar ao Programa Nacional de Informática na Educação-PROINFO, criado pela Portaria no 522/MEC, de 1997, que pretendia diminuir as diferenças de oportunidade de formação entre os alunos do sistema público de ensino e os da escola particular, cada vez mais informatizada, perseguindo os seguintes objetivos:

1) Melhorar a qualidade do processo de ensino-aprendizagem;

2) Possibilitar a criação de uma nova ecologia cognitiva nos ambientes escolares mediante incorporação adequada das novas tecnologias da informação pelas escolas;

3) Propiciar uma educação voltada para o desenvolvimento científico e tecnológico;

4) Educar para uma cidadania global numa sociedade tecnologicamente desenvolvida (BRASIL, 1997a).

A intenção, conforme Tavares (2002, p. 6), "era formar 25 mil professores e atender a 6,5 milhões de estudantes, através da compra e distribuição de 100 mil computadores interligados à Internet". A experiência, consoante avaliação realizada, mostrou uma grande evolução da presença de computadores nas escolas públicas brasileiras e um avanço na formação de recursos humanos para trabalhar com a tecnologia no processo educacional. No que concerne às metas e ao desenho operacional, foi exitosa, pois, segundo dados do MEC (BRASIL, 2008b), referentes ao período de 1996 a 2002, capacitou 137.911 professores, atendeu 6 milhões de alunos e instalou 53.895 computadores. 
A partir de dezembro de 2007, recebeu nova denominação, pelo Decreto 6.300/2007, passando a chamar-se Programa Nacional de Tecnologia Educacional (Prolnfo). Este, como seus antecessores, também se voltou para a disseminação do "uso pedagógico das tecnologias de informática e telecomunicações nas escolas públicas de ensino fundamental e médio pertencentes às redes estadual e municipal" (BRASIL, 1997a), capacitando professores e atendendo os estudantes, por meio da compra e distribuição de computadores interligados à Internet.

Para isso, valendo-se do modelo organizacional do seu antecessor, assentou-se numa engenharia institucional que, como exposto abaixo, combina colaboração com autonomia e descentralização.

\section{DESENHO INSTITUCIONAL E ORGANIZACIONAL DO PROINFO}

O Prolnfo tem por base, conforme o art. 2o do Decreto 6.300/07, o "regime de colaboração entre a União, os Estados, o Distrito Federal e os Municípios, mediante adesão" (BRASIL, 2007a). A União participa através do Ministério da Educação e do Fundo Nacional de Desenvolvimento da Educação (FNDE); os estados e municípios, por meio de suas respectivas secretarias e da co-participação, prevista desde as diretrizes do PROINFO de 1997, das organizações de secretários estaduais - Conselho Nacional de Secretários Estaduais de Educação (CONSED) - e de secretários municipais - União dos Dirigentes Municipais de Educação (UNDIME).

A União encarregada pela implantação dos ambientes tecnológicos, capacitação dos agentes educacionais e oferta de conteúdos educacionais, custeia, por meio "das dotações orçamentárias anualmente consignadas ao Ministério da Educação e ao Fundo Nacional de Desenvolvimento da Educação - FNDE" (BRASIL, 2007a), coordena, acompanha e avalia o Programa. Os encargos do Ministério da Educação são estabelecidos no art. 3o do Decreto no 6300/2007 (BRASIL, 2007a), nos seguintes termos:

O Ministério da Educação é responsável por:

I - implantar ambientes tecnológicos equipados com computadores e recursos digitais nas escolas beneficiadas;

II - promover, em parceria com os Estados, Distrito Federal e Municípios, programa de capacitação para os agentes educacionais envolvidos e de conexão dos ambientes tecnológicos à rede mundial de computadores;

III - disponibilizar conteúdos educacionais, soluções e sistemas de informações.

Estados, Distrito Federal e municípios, por sua vez, são responsáveis pela provisão da infraestrutura, viabilização e incentivo da capacitação dos professores, pelos recursos humanos e pelo suporte e manutenção dos equipamentos. Nos termos do art. 4o do Decreto 6.300/2007 (BRASIL, 2007a):

Os Estados, o Distrito Federal e os Municípios que aderirem ao Prolnfo são responsáveis por:

I - prover a infra-estrutura necessária para o adequado funcionamento dos ambientes tecnológicos do Programa; 
II - viabilizar e incentivar a capacitação de professores e outros agentes educacionais para utilização pedagógica das tecnologias da informação e comunicação;

III - assegurar recursos humanos e condições necessárias ao trabalho de equipes de apoio para o desenvolvimento e acompanhamento das ações de capacitação nas escolas; e

IV - assegurar suporte técnico e manutenção dos equipamentos do ambiente tecnológico do Programa, findo o prazo de garantia da empresa fornecedora contratada.

A execução dessas ações, em cada unidade - estado ou município - fica a cargo do Núcleo de Tecnologia Educacional (NTE). Esses núcleos são estruturados com laboratórios, coordenadores e professores multiplicadores, especialistas em tecnologias de informação e comunicação. Segundo o documento "Núcleos de Tecnologia Educacional - caracterização e critérios para criação e implantação" (BRASIL, 1997b), cabe aos núcleos:

a) Capacitar professores e técnicos das unidades escolares de sua área de abrangência;

b) Prestar suporte pedagógico e técnico às escolas (elaboração de projetos de uso pedagógico das TIC, acompanhamento e apoio à execução, etc...);

c) Realizar pesquisas e desenvolver e disseminar experiências educacionais; e

d) Interagir com as Coordenações Regionais do Prolnfo e com a Coordenação Nacional do Programa no Ministério da Educação-MEC, no sentido de garantir a homogeneidade da implementação e o sucesso do Programa (BRASIL, 1997b).

Além desses, em cada estado, uma Coordenação, segundo o Manual do Sistema de Gestão Tecnológica (SIGETEC) (BRASIL, 2008a, p. 7), encarrega-se de:

introduzir o uso das tecnologias de informação e comunicação nas escolas da rede pública, [...] articular as atividades desenvolvidas sob sua jurisdição, em especial as ações dos Núcleos de Tecnologia Educacional (NTEs) e União Nacional dos Dirigentes Municipais de Educação (UNDIMEs).

Essas coordenações também escolhem as escolas estaduais, em cada segmento em que se ramifica o Programa - urbano, rural ou substituição dos equipamentos -, entre aquelas préselecionadas pelo Ministério da Educação com base no Censo Escolar e menor IDEB. A escolha deve obedecer aos critérios definidos em cada um dos segmentos (BRASIL, 2008a, p. 8).

- Urbano: as escolas devem ser públicas, ativas, com energia elétrica, mais de 20 alunos; não devem ser exclusivamente de educação infantil (creche, pré-escola e jardim de infância); não devem possuir laboratórios do Prolnfo, nem laboratório de informática com número superior a 30 computadores.

- Rural: as escolas devem ser públicas, ativas, com energia elétrica, mais de 20 alunos; não devem ser exclusivamente de educação infantil (creche, pré-escola e jardim de infância); não devem possuir laboratórios do Prolnfo.

Nos casos de substituição dos equipamentos antigos, "upgrade" na linguagem do Manual, os critérios são os mesmos na área urbana e na rural, assim como aqueles a serem adotados 
pelas prefeituras para escolher, dentre as selecionadas pelo Ministério, as escolas municipais. Como ocorre esse processo nos municípios é o que se expõe a seguir.

\subsection{O Prolnfo nos municípios: adesão e implementação}

A seleção é o segundo passo no processo de adesão ao Programa pelo ente federado. O primeiro é a assinatura do Termo de Adesão que, segundo o MEC (BRASIL, 1997b), é o ato que representa o compromisso com os objetivos e estratégias do Programa e seus resultados.

Esta ação se concretiza através do cadastro do prefeito no Sistema de Gestão Tecnológica (SIGETEC), acompanhado de documentos pessoais e funcionais e da inserção das seguintes informações das escolas selecionadas: nome da escola, UF, município, código INEP e a situação da infraestrutura que irá acomodar os computadores, incluindo fotos.

É uma etapa que se conclui quando todas as informações são prestadas, principalmente aquelas relativas ao local onde será instalado o laboratório que, comprovadamente, segundo o MEC (BRASIL, 2011), deve atender os seguintes critérios:

1. O laboratório de informática deverá estar protegido de forma adequada contra agentes agressivos como, por exemplo, areia, poeira, chuva;

2. A temperatura ambiente deve ser de no máximo 30 o C;

3. Tomadas elétricas comuns não podem ser compartilhadas com a rede elétrica dos equipamentos de informática;

4. Ausência de falhas estruturais na alvenaria do prédio;

5. Piso adequado - madeira, pedra, cimento liso, vinil, cerâmica ou equivalente;

6. Exigências mínimas da rede elétrica: fornecimento de energia elétrica de $110 \mathrm{~V}$ ou $220 \mathrm{~V}$, com capacidade de pelo menos 10KVA;

7. Quadro de distribuição de energia elétrica exclusivo para os equipamentos de informática;

8. Aterramento do quadro e seus circuitos (não usar o neutro da rede), com resistência menor ou igual a 10 (BRASIL, 2011, p. 4-6).

A satisfação dessas exigências credencia a escola a receber os equipamentos que, até três anos, têm assistência técnica garantida contra defeitos de fabricação assegurados pelo fornecedor. Depois, a responsabilidade de manutenção é do NTE.

O Programa, então, se desenvolve como disposto na Figura 1, abaixo. 


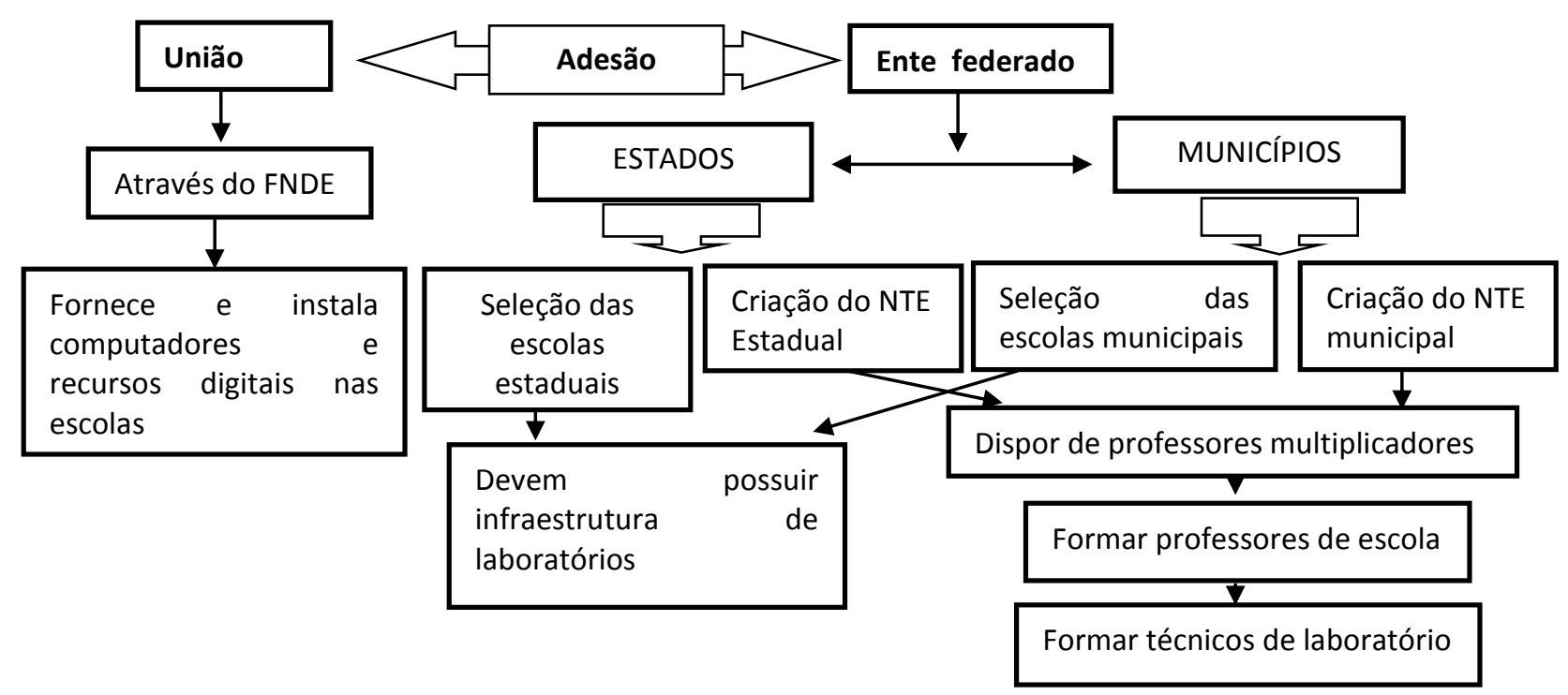

FIGURA 1. Desenho institucional e organizacional do Prolnfo.

Fonte: Elaboração própria a partir de informações do MEC (BRASIL, 1997b, 2008a) e do Decreto 6.300/07 (BRASIL, 2007a).

O Prolnfo depende, portanto, da formação de uma complexa rede de agentes públicos Secretaria de Educação Básica, Fundo Nacional de Desenvolvimento da Educação, secretarias, escolas - e de agentes não públicos - CONSED e UNDIME. Alguns deles, como o Ministério da Educação, através da Secretaria de Educação Básica e do Fundo Nacional de Desenvolvimento da Educação, são encarregados de prover, acompanhar, supervisionar; outros, como as secretarias estaduais e municipais, de implementar e executar, bem como criar e operacionalizar os NTEs.

Essa engenharia institucional favorece a assunção de responsabilidades dos entes federados para com a introdução das novas tecnologias na educação? É o que se examina a seguir, a partir do delineamento do modelo federativo vigente adotado na Constituição Federal de 1988.

\section{FEDERALISMO E INDUÇÃO À DESCENTRALIZAÇÃO NA EDUCAÇÃO BRASILEIRA CONTEMPORÂNEA}

O sistema federativo, estabelecido desde a primeira constituição republicana, adquiriu novo desenho com a Constituição Federal de 1988, constituindo-se, agora, não apenas pela União e estados, mas também pelos municípios. "Caso único nos sistemas federais contemporâneos", segundo Almeida e Carneiro (2003, p. 126). Isso, se por um lado, confere autonomia - política, financeira, administrativa e legislativa -, por outro, confere atribuições aos três entes, algumas comuns, outras concorrentes.

A área social - educação, saúde, assistência social, combate à pobreza, habitação, meio ambiente, dentre outras - está entre as atribuições comuns, prevendo o Parágrafo Único do art. 23 da Constituição Federal de 1988 a instituição de normas definidoras de cooperação "tendo em vista o equilíbrio do desenvolvimento e do bem-estar em âmbito nacional" (BRASIL, 1988). Assim, como dizem Almeida e Carneiro (2003, p. 128), substituía-se "um modelo totalmente centralizado em certas áreas e competitivo em outras por uma modalidade de federalismo cooperativo, caracterizado pela existência de funções compartilhadas entre as diferentes esferas de governo". 
Isso requeria descentralização, isto é, que encargos, antes de responsabilidade da União, fossem repassados para os governos subnacionais, o que demandou tanto a fixação de leis e normas, como, na expressão de Arretche (2011, p. 57), "estratégias de indução" para que um ente federado se dispusesse a oferecer ou gerenciar determinada política. É que, explica a autora,

[...] em Estados Federativos, a assunção de atribuições de gestão em políticas públicas depende da decisão soberana dos governos locais - salvo expressas imposições constitucionais e dado que esta decisão é resultado de um cálculo destas administrações quanto aos custos e benefícios nela implicados, a extensão da descentralização depende, em grande parte, da estrutura de incentivos associada à política particular.

Uma estrutura de incentivos, como chama Arretche (2011), ou uma "estratégia de indução", na expressão de Souza e Carvalho (1999), consiste na

[...] definição de regras de operação e mecanismos que incentivem a adesão do nível de governo a que se dirigem (estados ou municípios), propiciando-lhes a capacitação técnico-administrativa necessária, reduzindo os custos financeiros envolvidos na instalação da infraestrutura ou na manutenção dos serviços descentralizados, transferindo recursos em escala compatível com as novas atribuições e elevando o volume da receita disponível (SOUZA; CARVALHO, 1999, p. 205)

$\mathrm{Na}$ área educacional, a estrutura de incentivos para a transferência de encargos de um ente para o outro, deu-se, inicialmente, como uma das mais importantes iniciativas, através da Lei no 9.424/96 que regulamenta o Fundo de Manutenção e Desenvolvimento do Ensino Fundamental e de Valorização do Magistério (FUNDEF).

O FUNDEF é um mecanismo contábil que distribui recursos entre cada estado e seus municípios, "segundo uma proporção do número de alunos matriculados por cada um deles, tendo como base de cálculo um valor/aluno/ano sobre a média do custo aluno/ano feita para todos os Estados do Brasil" (MENEZES, 1999, p. 174). Desse modo, os recursos, inclusive a complementação da União, ficam condicionados ao número de alunos matriculados, incentivando municípios e estados a exercer as competências definidas constitucionalmente e a ampliar suas matrículas, até mesmo, como constatou Verhine (1999, p. 142), a competir por novos alunos. "Pela primeira vez na história do país", diz Verhine (1999, p. 142), "ficou economicamente vantajoso matricular novos alunos".

O FUNDEF vigorou, como estava previsto na lei de instituição, até 2006. Para substituí-lo, foi "criado pela Emenda Constitucional no 53/2006 e regulamentado pela Lei 11.494/2007 e Decreto no 6.253/2007" (SOUSA; BUENO, 2009, p. 07) o Fundo de Manutenção e Desenvolvimento da Educação Básica e de Valorização dos Profissionais da Educação - FUNDEB. É também um fundo especial de natureza contábil, de âmbito estadual, formado, na quase totalidade, por recursos provenientes dos impostos e transferências dos estados, Distrito Federal e municípios e, a título de complementação, por uma parcela de recursos federais.

A legislação do FUNDEB beneficiou-se da experiência do FUNDEF, inovando alguns de seus aspectos, aperfeiçoando e mantendo outros (SENA, 2008). Entre as inovações, incluem-se, segundo Sena (2008): 
forma diferente de evitar a implantação abrupta: enquanto no Fundef optou-se por um prazo de carência de um ano até a implantação compulsória, no caso do Fundeb optou-se pelo gradualismo, com a inserção progressiva dos recursos oriundos dos impostos [...]; possibilidade de que a conta única e específica seja no Banco do Brasil ou na Caixa Econômica Federal [...] (SENA, 2008, p. 324-325).

Dentre os aspectos que representam aperfeiçoamento, o autor destaca os seguintes:

todas as etapas da educação básica passaram a contar com um mecanismo de financiamento [...]; a regra da complementação da União, antes definida em legislação ordinária, e nunca respeitada pelos governos do período, foi constitucionalizada [...]; a vedação do uso da fonte do salário-educação para a complementação da União; a preocupação com o aperfeiçoamento do desenho institucional dos conselhos de acompanhamento e controle social [...]; previsão da fixação em lei de piso salarial profissional nacional para o magistério; cômputo das matrículas, para recebimento dos recursos do fundo, tendo como critério obrigatório o atendimento ao âmbito de atuação prioritária, isto é, à função própria (educação infantil e ensino fundamental, para os municípios, e ensino médio e ensino fundamental, para os estados) (SENA, 2008, p. 322-323).

As características do FUNDEF mantidas, por sua vez, foram:

natureza contábil do fundo; contas únicas e específicas com repasses automáticos; controle social e acompanhamento exercido por conselhos nas três esferas federativas; destinação a ações de manutenção e desenvolvimento do ensino na educação básica [...]; possibilidade de retificação dos dados do censo por demanda dos entes federados; complementação da União (SENA, 2008, p. 322).

Mesmo diante de inovações e aperfeiçoamentos, para SENA (2008), os avanços concretos em relação ao FUNDEF que se destacaram foram:

um equacionamento razoável da questão da complementação da União (considerando-se que os valores são mínimos e podem e devem ser ampliados até, ao menos, o patamar de gastos praticado pela União em 1995) e a aposta num espaço federativo de negociação como a Comissão Intergovernamental de Financiamento para a Educação Básica de Qualidade (SENA, 2008, p. 339).

Além disso, complementa o autor, "impulsionou a definição de piso salarial para o magistério" (SENA, 2008, p. 339). O novo fundo manteve, contudo, o mecanismo indutório anterior: os recursos condicionados ao número de matrículas.

Esse mecanismo, desde o FUNDEF, possibilitou a elevação da taxa de escolarização líquida no ensino fundamental de 87,5\% em 1994 para 95,3\% em 1998 e 95,4\% em 1999 (IBGE, 2000), o que, segundo Oliveira e Teixeira (2008, p. 4), "foi acompanhado do acirramento do processo de municipalização. Se, em 1997, os municípios atendiam a $41 \%$ dos alunos nesse nível de ensino, já em 2002 esse percentual atingia 54\%". Elevação também ocorreu na taxa de escolarização líquida do ensino médio, após a implantação do FUNDEB: em 2006, era 48\%, em 2009, dois anos após o Fundo, já era 51,6\% e em 2012, 54, 4\% (BRASIL, 2013a).

Isto mostra o poder dos recursos econômicos numa estratégia de indução associada a requisitos ou exigências "postos pela engenharia operacional" da política e normatizados por 
"regras constitucionais" (ARRETCHE, 2011, p. 57). Estes, segundo Arretche (2011, p. 57), "constituem elementos importantes da decisão local pela assunção de competências de gestão de políticas públicas".

Outro mecanismo de incentivo para que estados e municípios assumam encargos na educação é a quota federal do Salário Educação ${ }^{1}$ - um terço dos recursos arrecadados. Desta feita, diferentemente do FUNDEF ou FUNDEB, trata-se de transferências voluntárias, e os recursos destinam-se ao desenvolvimento de ações específicas. Consequentemente, tanto a União, como os demais entes federativos exercem o poder discricionário; o primeiro, escolhendo o que vai ser financiado, e os demais, aceitando ou não o que é oferecido.

O Prolnfo é um desses programas financiados pelo FNDE. Nesse caso, a engenharia institucional favorece a assunção de responsabilidades dos entes federados para com a introdução das novas tecnologias na educação?

\section{A ESTRATÉGIA DE DESCENTRALIZAÇÃO NO PROINFO}

No desenho institucional do Prolnfo, as responsabilidades são divididas entre a União e os entes federados. Ao primeiro cabe disponibilizar os recursos, indicar as escolas candidatas a recebê-los, coordenar, acompanhar e avaliar o Programa. Em síntese, a União:

a) Dota os laboratórios das escolas escolhidas com a infraestrutura física e de computação e comunicação necessária ao processo de ensino e aprendizagem;

b) Capacita os agentes educacionais das escolas escolhidas;

c) Oferece conteúdos educacionais;

d) Coordena, acompanha e avalia o Programa.

Aos demais entes federados, caso façam adesão ao Prolnfo, isto é, aceitem desenvolvê-lo, cabe-Ihes escolher, entre as escolas indicadas, aquelas que receberão os recursos e implementar o Programa, inclusive com o pessoal e meios necessários a sua manutenção.

Desse modo, a União exerce sua competência redistributiva, prestando assistência técnica e financeira, e os entes federados, por um lado, têm recursos para a aquisição de computadores e demais equipamentos (impressora, scanner, data-show, lousa digital, etc.), necessários à implantação de ambientes tecnológicos nas escolas e, por outro, disponibilizam meios para a melhoria do ensino, inclusive favorecendo a permanência e até mesmo a atração de novos alunos.

O Prolnfo, então, reduz os custos e pode favorecer os ganhos. Desse modo, a União estimula a introdução de novas tecnologias e os entes federados têm a possibilidade de melhorar a qualidade do ensino que oferecem através da tecnologia e, consequentemente, podem manter ou atrair alunos.

De qualquer modo, esta é uma descentralização que se assenta na tradicional divisão de função: um decide (planeja, financia, controla) e outro executa. Todavia, todas as decisões do primeiro dependem de um executor, o qual terá a responsabilidade da implementação conforme

\footnotetext{
${ }^{1}$ O salário-educação é uma contribuição social destinada ao financiamento de programas, projetos e ações voltados para o financiamento da educação básica pública, prevista no artigo 212, § 5o, da Constituição Federal, regulamentada pelas leis nํs 9.424/96, 9.766/98, Decreto no 6003/2006 e Lei n 11.457/2007 (BRASIL, 2014).
} 
o planejado. Isso deu certo? Conforme dados do Ministério da Educação (BRASIL, 2005, 2006, 2007b, 2008c, 2012, 2013a), da UNB (2002) e da CGU (BRASIL, 2013b), até 2013, um total de 92\% dos 5.561 municípios brasileiros já havia aderido ao Programa, foram implantados mais de 100.000 laboratórios e adquiridos mais de 1.000 .000 de computadores e periféricos (servidores, impressoras, scanners).

A avaliação da Controladoria Geral da União - CGU (BRASIL, 2013b), realizada em 2013, constatou que:

- Quase a totalidade dos laboratórios foi entregue com as configurações iguais ou superiores às exigidas no edital;

- Na amostra analisada, houve um percentual de 30,1\% de laboratórios entregues e não instalados;

- Houve fragilidade na capacitação dos professores, o que impediu o uso das tecnologias no processo de ensino-aprendizagem;

- Mesmo diante dos "avanços proporcionados pelo Prolnfo na inclusão digital, a sua função precípua, o uso pedagógico da informática nas escolas públicas de educação básica não foi plenamente atingido" (BRASIL, 2013b, p. 38).

Os dados apresentados pela CGU mostram que a União cumpre sua responsabilidade de dotar as escolas com as tecnologias, mas estados e municípios não cumprem ou cumprem parcialmente as suas, no que se refere à capacitação de professores para utilização pedagógica das tecnologias da informação e comunicação e ao suporte técnico e manutenção dos equipamentos do ambiente tecnológico do Programa, após findar o prazo de garantia da empresa fornecedora contratada. Chama a atenção o número de laboratórios e computadores que continuam sendo colocados à disposição das escolas, apesar da constatação de que não são utilizados ou mesmo de que não há aferição do uso pedagógico das tecnologias de informática e telecomunicações nas escolas públicas.

A engenharia institucional assenta-se na seguinte regra: a União decide e financia as novas tecnologias; os estados e municípios executam, responsabilizando-se pelos custos de manutenção, inclusive de pessoal e instalações. Nesse caso, a condição de acesso ao recurso é que haja adesão e assunção de compromissos. Em outros termos, a União espera que, com a liberação de recursos para a aquisição de equipamentos, estados e municípios adotem as novas tecnologias em suas escolas, dispondo de pessoal e recursos para manutenção.

Desse modo, estados e municípios, além de não terem aumentado o volume da receita disponível, vez que os recursos repassados destinam-se à aquisição dos equipamentos, não têm os seus custos reduzidos. Pelo contrário, eles são aumentados seja com a remuneração dos professores multiplicadores, dos técnicos do Núcleo, da segurança do laboratório, do mobiliário, das instalações elétricas (tomadas e aterramento), seja com a manutenção da infraestrutura dos laboratórios. Então, os custos são maiores do que os benefícios.

A isso se soma o fato de que, nessa engenharia institucional, não há qualquer vínculo entre liberação de recursos e cumprimento das atribuições pactuadas ou mesmo destas com novos aportes de recursos. Assim, o programa segue um ciclo: estados e municípios auferem os benefícios do Programa, reduzem os seus custos no que tange à infraestrutura de informática e implementam-no precariamente. Como não há uma estratégia que os induza a efetivar o que estabelece o Programa, os objetivos não são atingidos plenamente. 


\section{CONCLUSÃO}

Este artigo verificou se a engenharia institucional do Prolnfo favorece a assunção de responsabilidades dos entes federados com a introdução das novas tecnologias na educação, partindo da compreensão de que, num federalismo em que os entes federativos são autônomos, a descentralização, isto é, a passagem de uma atribuição de uma instância para outra, depende de incentivos.

Na educação, os incentivos oferecidos pelo FUNDEF e depois pelo FUNDEB possibilitaram a ampliação do número de matrículas nos ensinos fundamental e médio. Neles, a fatia destinada aos estados e municípios, bem como a complementação da União dependem do número de alunos matriculados, incentivando-os a ampliar suas matrículas e, desse modo, cumprir as responsabilidades definidas na constituição.

Esse não é o modelo do Prolnfo. Seu modelo se assenta numa divisão do trabalho em que a União financia, coordena a implantação dos ambientes tecnológicos, acompanha e avalia o Programa, e os demais entes federativos administram, executam e mantêm as ações, conforme determinado pelo Decreto 6.300/07. Não há, como no FUNDEF ou FUNDEB, condicionalidade para receber os recursos do Programa, salvo, a adesão. Vale dizer, não há algo que os induza a introduzir as novas tecnologias nas escolas.

Portanto, a estratégia desenhada favoreceu a montagem da infraestrutura, oferecendo os meios, complementando-os ou incentivando-os a introduzir novas tecnologias nas escolas. Isso porque, apesar de estados e municípios estarem constitucionalmente obrigados a aplicar recursos na educação básica, não significa que contemplem, nas ações de manutenção e desenvolvimento do ensino ( $\mathrm{MDE}$ ), tecnologias de informação e comunicação. Esta é uma escolha e, por conseguinte, depende da discricionariedade do gestor ou de um mecanismo indutor que potencialize os ganhos e minimize os custos. A ausência deste e, principalmente, a ampliação dos custos sem qualquer garantia de ganhos, atua desfavoravelmente na assunção das atribuições pactuadas quando da adesão ao Prolnfo.

A engenharia institucional, portanto, não favoreceu satisfatoriamente, como objetivava o programa, o uso pedagógico das tecnologias de informação e comunicação nas redes públicas de educação básica, ainda que tenha patrocinado a instalação de laboratórios, isto é, tenha disponibilizado os meios para a inclusão digital desejada. É que, como não há uma imposição constitucional nesse sentido, a assunção dessa função depende da discricionariedade do ente subnacional para o que muito contribuiria um mecanismo indutor que potencializasse os ganhos e minimizasse os custos.

Não se pode esquecer, como já alertou Arretche (2011), que "a grande maioria dos municípios brasileiros caracteriza-se por baixa capacidade econômica, expressiva dependência das transferências fiscais e fraca tradição administrativa". Por conseguinte, a implementação de políticas ou programas depende de engenharias institucionais que removam obstáculos ou ofereçam compensações.

\section{REFERÊNCIAS BIBLIOGRÁFICAS}

1. ALMEIDA, Maria Hermínia Tavares; CARNEIRO, Leandro Piquet. Liderança local, democracia e políticas públicas no Brasil. Opinião Pública [online], Campinas, v. 9. 2003, n.1, p. 124-147, 
mar. 2003. Disponível em: <http://www.scielo.br/pdf/op/v9n1/16154.pdf>. Acesso em: 01 out. 2014.

2. ANDRADE, Pedro Ferreira de; LIMA, Maria C. M. de Albuquerque. Projeto EDUCOM. Brasília: MEC/OEA, 1993.

3. ARRETCHE, Marta. Estado Federativo e políticas sociais: determinantes da descentralização. 3. ed. Rio de Janeiro: Revan; São Paulo: FAPESP, 2011.

4. BRASIL. Ministério da Educação e do Desporto. Portaria. no 522, de 9 de abril de 1997. Cria o Programa Nacional de Informática na Educação. Brasília-DF, 1997a. Disponível em: <http://www.dominiopublico.gov.br/pesquisa/DetalheObraForm.do?select_action=\&co_obr $a=22148>$. Acesso em: 24 jan. 2014.

5. _ Ministério da Educação. Núcleos de Tecnologia Educacional - NTE. Caracterização e Critérios para Criação e Implantação. Brasília-DF, 1997b. Disponível em: < https://www.fnde.gov.br/sigetec/upload/manuais/cat_crit_NTE.doc>. Acesso em: 22 fev. 2014.

6. Constituição (1988). Constituição da República Federativa do Brasil. Brasília, DF: Senado, 1988.

7.

Ministério da Educação; UNB. Prolnfo: perspectivas e desafios - Relatório Preliminar de Avaliação. Brasília-DF, 2002. Disponível em: < http://dominiopublico.mec.gov.br/pesquisa/DetalheObraForm.do?select_action=\&co_obra= 22151 >. Acesso em: 03 jan. 2014.

8. _ Fundo Nacional de Desenvolvimento da Educação (FNDE). Relatório de gestão do FNDE exercício de 2004. Brasília: FNDE, 2005.

9. __ Fundo Nacional de Desenvolvimento da Educação (FNDE). Relatório de gestão do FNDE exercício de 2005. Brasília: FNDE, 2006.

10. Presidência da República. Casa Civil. Subchefia para Assuntos Jurídicos. Decreto no 6.300, de 12 de dezembro de 2007. Dispõe sobre o Programa Nacional de Tecnologia Educacional - Prolnfo. Diário Oficial da República Federativa do Brasil, Poder Executivo. Brasília, DF, 2007a. Disponível em: <http://www.planalto.gov.br/ccivil_03/_Ato20072010/2007/Decreto/D6300.htm>. Acesso em: 24 jan. 2014.

11. Fundo Nacional de Desenvolvimento da Educação (FNDE). Relatório de gestão do FNDE exercício de 2006. Brasília: FNDE, 2007b.

12. - Ministério da Educação. Manual SIGETEC - Sistema de Gestão Tecnológica. Adesão ao Prolnfo utilizando o sistema SIGETEC. Brasília-DF, 2008a. Disponível em: <http://webeduc.mec.gov.br/linuxeducacional/manuais/SIGETEC.pdf>. Acesso em: $21 \mathrm{fev}$. 2014.

13. . Ministério da Educação. Relatório de atividades 1996/2002. Brasília: DIED/SEED, 2008b.

14. Ministério da Educação. Prolnfo: 92\% dos municípios já aderiram. Brasília-DF, 2008c.

Disponível em: <http://portal.mec.gov.br/index.php?option=com_content\&task=view\&id=10782>. Acesso em: 12 nov. 2014.

15. Ministério da Educação. Programa Nacional de Tecnologia Educacional - Prolnfo. 
Cartilha de Recomendações para a Montagem de Laboratórios de Informática nas Escolas Urbanas. Brasília-DF, 2011. Disponível em: < https://www.fnde.gov.br/sigetec/upload/manuais/cartilhaurbano_2011.pdf >. Acesso em: 24 fev. 2014.

16. Fundo Nacional de Desenvolvimento da Educação (FNDE). Relatório de gestão do FNDE exercício de 2011. Brasília: FNDE, 2012.

17. Fundo Nacional de Desenvolvimento da Educação (FNDE). Relatório de gestão do FNDE exercício de 2012. Brasília: FNDE, 2013a.

18. _. Fundo Nacional do Desenvolvimento da Educação (FNDE). Entendendo o Salário Educação. Brasília-DF, 2014. Disponível em: < http://www.fnde.gov.br/financiamento/salario-educacao/salario-educacao-entendendo-o>. Acesso em: 13 nov. 2014.

19. CONTROLADORIA GERAL DA UNIÃO (CGU). Relatório de Avaliação da Execução de Programas de Governo no 16 - Infraestrutura de Tecnologia para a educação básica pública (Prolnfo). Brasília-DF, 2013b. Disponível em: < http://sistemas.cgu.gov.br/relats/uploads/2506_ \%20RAv\%2016\%20-\%20PROINFO.pdf>. Acesso em: 01 fev. 2014.

20. INSTITUTO BRASILEIRO DE GEOGRAFIA E ESTATÍ́sTICA - IBGE. Taxa líquida de escolarização por níveis de ensino. Censo Demográfico, 2000. Disponível em: < http://seriesestatisticas.ibge. gov.br/series.aspx?vcodigo=SEE17>. Acesso em: 23 nov. 2014.

21. MENEZES, Jaci Maria Ferraz de. Descentralização, municipalização: democratização? A tensão entre centralização e descentralização da Educação na Bahia. Revista da FAEEB, Salvador, v. 12, p. 153-182, jul./dez. 1999.

22. MORAES, Maria Cândida. Informática Educativa no Brasil: uma história vivida, algumas lições aprendidas. Revista Brasileira de Informática na Educação, Florianópolis, v. 1, n. 1, p. 19-44, set. 1997.

23. OLIVEIRA, Rosimar de Fátima; TEIXEIRA, Beatriz de Basto. As políticas de financiamento da educação na última década: do FUNDEF ao FUNDEB. In: IV Simpósio Internacional O Estado e as Políticas Educacionais no Tempo Presente, 2008, Uberlândia. Anais do IV Simpósio Internacional O Estado e as Políticas Educacionais no Tempo Presente. Uberlândia: UFU, 2008, p. 1-14.

24. SENA, Paulo. A legislação do Fundeb. Cadernos de Pesquisa, Brasília, v.38, n.134, p. 319-340, maio/ago. 2008.

25. SOUSA, Everaldo Sebastião de; BUENO, Marlene Nunes Freitas. Manual de Orientação FUNDEB. Goiânia: MP, 2009.

26. SOUZA, Celina; CARVALHO, Inaiá M. M. de. Reforma do Estado, descentralização e desigualdades. Lua Nova, São Paulo, n. 48, p. 187-212, dez. 1999.

27. TAVARES, Neide Rodriguez Barea. História da informática educacional no Brasil observada a partir de três projetos públicos. São Paulo: Escola do Futuro, 2002. Disponível em: <http://www.lapeq.fe.usp.br/textos/te/tepdf/neide.pdf>. Acesso em: 03 set. 2014.

28. VALENTE, José Armando; ALMEIDA, Fernando José de. Visão analítica da informática na educação no Brasil: a questão da formação do professor. Revista Brasileira de Informática 
na Educação, Florianópolis, v.1, n. 1, p. 45-60, set. 1997.

29. VERHINE, R. E. O FUNDEF: suas implicações para a descentralização do ensino e o financiamento da educação no Brasil. Revista da FAEEB, Salvador, v. 12, p. 131-151, jul./dez. 1999. 